\title{
CAVITATION EROSION PROPERTIES OF A NICKEL-FREE HIGH-NITROGEN Fe-Cr-Mn-N STAINLESS STEEL
}

\author{
RAZISKAVE ODPORNOSTI PROTI KAVITACIJSKI EROZIJI \\ Z DUŠIKOM LEGIRANEGA Fe-Cr-Mn-N NERJAVNEGA JEKLA
}

\author{
Yanxin Qiao' ${ }^{1}$ Xiang Cai ${ }^{1}$, Yipeng Chen ${ }^{1}$, Jie Cui ${ }^{2}$, Yanbing Tang ${ }^{3}$, Huabing $\mathrm{Li}^{4}$, \\ Zhouhua Jiang 4 \\ 1Jiangsu University of Science and Technology, School of Materials Science and Technology, No.2 Mengxi Road, Zhenjiang, China \\ 2Jiangsu University of Science and Technology, School of Naval Architecture and Ocean Engineering, No.2 Mengxi Road, Zhenjiang, China \\ 3Jiangsu University of Science and Technology, Marine Equipment and Technology Institute, No.2 Mengxi Road, Zhenjiang, China \\ ${ }^{4}$ Northeastern University, School of Metallurgy, No.2 Wenhua Road, Shenyang, China \\ yxqiao@just.edu.cn, cuijie2006@hotmail.com
}

Prejem rokopisa - received: 2017-03-22; sprejem za objavo - accepted for publication: 2017-05-12

doi:10.17222/mit.2017.034

\begin{abstract}
The cavitation erosion behaviour of a nickel-free high-nitrogen stainless steel was investigated using 20-kHz vibratory cavitation test equipment and analysed by scanning electron microscopy (SEM). The potentiodynamic polarization was measured to clarify the role of corrosion on the cavitation erosion of tested steel. The results indicated that the cavitation erosion damage in tested steel occurred initially at the grain boundary, twin boundary and interface between the precipitate and the matrix. Cavitation shifted the corrosion potential to the cathodic direction in $0.5-\mathrm{M} \mathrm{NaCl}$ solution and leading to a corrosion-current density almost two orders higher than that under static conditions. In the total cumulative mass loss under cavitation erosion-corrosion conditions, the mechanical effect played a key role in a $0.5-\mathrm{M} \mathrm{NaCl}$ solution and the synergistic effect induced by electrochemical and mechanical amounts to $14.78 \%$ of the total mass loss.

Keywords: cavitation erosion, high-nitrogen stainless steel, corrosion, synergistic effect
\end{abstract}

Za raziskave odpornosti proti kavitacijski eroziji z dušikom brez niklja, legiranega nerjavnega jekla, so uporabili preizkuse z 20 $\mathrm{kHz}$ vibracijsko kavitacijo in vrstično elektronsko mikroskopijo (SEM). Zato, da bi pojasnili vlogo kavitacijske korozije pri preiskovanem jeklu, so izmerili potenciodinamsko polarizacijo. Rezultati so pokazali, da so se poškodbe zaradi kavitacijske erozije začele na mejah med zrni, mejah dvojčkov in na mejah med izločki in matrico. Preizkus v $0,5 \mathrm{M} \mathrm{NaCl}$ raztopini je pokazal, da je kavitacija premaknila korozijski potencial v katodni smeri, ki vodi h skoraj za dve stopnji višji korozijski gostoti električnega toka, kot je tisti v statičnih pogojih preizkušanja. V celoti je za kumulativno izgubo mase v $0,5 \mathrm{M}$ NaCl raztopini pod kavitacijsko erozijsko-korozijskimi pogoji ključno odgovoren mehanski učinek. Celotna izguba mase je znašala $14,78 \%$ zaradi istočasnega elektrokemijskega in mehansko induciranega delovanja.

Ključne besede: kavitacijska erozija, močno legirano dušikovo nerjavno jeklo, korozija, vpliv sinergijskega delovanja

\section{INTRODUCTION}

Cavitation erosion (CE) is a common problem in engineering parts in contact with a liquid. Plastic deformation and erosion damage on the metal surfaces are caused by the combination of shock loading and fatigue as a result of the stress generated by the repeated growth and collapse of cavities in the sheared liquid. ${ }^{1}$ Highnitrogen stainless steel (HNSS) has attracted much attention during the past several decades due to its well-balanced combination of excellent mechanical properties such as high strength and ductility, high work-hardening ability, high stress-induced martensite transformation and corrosion resistance. ${ }^{2,3}$ These attractive properties make HNSS good candidates for use in severe CE conditions.

HNSSs have been reported as suitable materials for applications in which erosive damage caused by CE, leading to a decrease in the large maintenance costs characteristics of hydraulic systems..$^{4,5} \mathrm{~S}$. Z. Luo $^{6}$ found that the excellent $\mathrm{CE}$ resistance of $\mathrm{CrMnN}$ was related to the good mechanical properties of the austenitic phase and the consumption of CE energy by plastic deformation involving slip and twinning. W. Liu found that the high $\mathrm{CE}$ resistance of $\mathrm{CrMnN}$ was mainly attributed to their high work-hardening ability and favourable cavitation crack propagation, i.e., parallel rather than perpendicular to the specimen surface. H. Berns ${ }^{8}$ attributed the better CE performance of HNSS to the effect of nitrogen in lowering the stacking-fault energy (SFE), leading to an increase in plasticity and work hardening. According to $\mathrm{W}$. T. $\mathrm{Fu}^{9}$ the high CE resistance of HNSS is related to its good mechanical properties induced by changes in the dislocation configurations, CE-induced mechanical twinning or formation of stacking faults and CE-induced phase transformation. P. Niederhofer ${ }^{10}$ found that the superior CE resistance of HNSS is caused by the strengthening effect of $\mathrm{N}$ and the low stacking-fault energy leading to intense cold work hardening. W. T. $\mathrm{Fu}^{11}$ studied the $\mathrm{CE}$ behaviour of $\mathrm{CrMnN}$ and showed that $\mathrm{CE}$ could induce a new martensite structure and delayed the progress of damage due to CE. D. J. Mill and 
R. D. Knutsen ${ }^{12}$ observed that the CE rate of $\mathrm{CrMnN}$ decreased with increasing amounts of cold working. They stressed the importance of the increase in yield strength, leading to a decrease of the plastic deformation inside individual grains during the early CE stages, to a delay of the onset of grain-boundaries extrusion and to a delay of the fatigue damage nucleation and growth. J. F. San$\operatorname{tos}^{13}$ found that the superior CE resistance of nitride 304L stainless steel is attributed to the high elastic energy. D. H. Mesa ${ }^{14}$ found that the high CE resistant of HNSS is due to its high hardness and great resistance to plastic deformation. The energy transferred by the shock waves caused by imploding bubbles, during the earliest stages of $\mathrm{CE}$, is greatly consumed elastically without leaving traces of plastic deformation on the surface.

In practice, many flow-handling components including pumps and valves operate in corrosion environments, where they are apparently subjected to the combined action of CE and corrosion. Although the stainless steel has a dense passive film, the corrosions still happen to some components contacting liquids in fluid machinery and become more obvious in the presence of CE, which causes a more serious damage of components because of the synergism of $\mathrm{CE}$ and corrosion. ${ }^{15,16} \mathrm{C}$. T. Kwok ${ }^{17}$ studied the $\mathrm{CE}$ behaviour of stainless steel in $3.5 \% \mathrm{NaCl}$ and found that corrosion and corrosion/erosion synergism play a negligible role.

Although a lot of publications on the CE performance of HNSS have been published, a systematic investigation of the effect of corrosion on the CE characteristics of HNSS was rarely reported in the literature. The aim of this study was to investigate the relative importance of $\mathrm{CE}$, corrosion and the synergism between them in the overall CE-corrosion damage of HNSS.

\section{EXPERIMENTAL PART}

\subsection{Materials and specimen preparation}

The HNSS used in this study was made by the dissolution of the raw materials in a high-vacuum furnace, followed by forging, hot rolling, cold rolling and then air cooling to room temperature. The HNSS was in the form of a round bar with a diameter of 20 $\mathrm{mm}$. The chemical composition of HNSS is listed in Table 1.

Table 1: Chemical composition of HNSS used in this study (w/\%)

\begin{tabular}{|c|c|c|c|c|c|c|c|c|}
\hline $\mathrm{C}$ & $\mathrm{Si}$ & $\mathrm{Mn}$ & $\mathrm{P}$ & $\mathrm{S}$ & $\mathrm{Cr}$ & $\mathrm{Mo}$ & $\mathrm{N}$ & $\mathrm{Fe}$ \\
\hline 0.048 & 0.24 & 15.96 & 0.004 & 0.017 & 18.44 & 2.23 & 0.66 & Bal. \\
\hline
\end{tabular}

The shape and dimension of the specimen used has been given in a previous study. ${ }^{15}$ Test surfaces were gradually ground down to 1000 grit and polished using 1.5- $\mu \mathrm{m}$ alumina powder before the $\mathrm{CE}$ test to observe the response of different phases to $\mathrm{CE}$ later. Specimens were degreased by immersion in acetone in an ultrasonic bath and were rinsed with distilled water, then dried and stored in desiccators. The specimens used for the microstructure observation was electrolytically etched in $10 \%$ ethanedioic acid reagent at $12 \mathrm{~V}$ for $90 \mathrm{~s}$.

\subsection{Test method}

CE was produced by a magnetostrictive-induced cavitation facility (Sonicator XL 2020) resonating at 20 $\mathrm{kHz}$ with a peak-to-peak amplitude of $60 \mu \mathrm{m}$. This test followed ASTM Standard G32-92. The cavitation tests were performed in distilled water and $0.5-\mathrm{M} \mathrm{NaCl}$. Reagent grade $\mathrm{NaCl}$ and distilled water were used. The temperature of the tested solution was maintained in the range $20 \pm 1{ }^{\circ} \mathrm{C}$.

For the CE test, the specimen was screwed into the horn and immersed into the test medium to a depth of 15 $\mathrm{mm}$. After each test period, the specimen was degreased, rinsed, dried, and weighed using an analytical balance (Sartorius BT25S) with an accuracy of $0.1 \mathrm{mg}$. To ensure the reproducibility of the results, every test was repeated three times. The potentiodynamic polarization tests were performed with a CS350 workstation (Corrtest Instrument, China). Using a platinum plate as the counterelectrode and a saturated calomel electrode (SCE) as the reference electrode, a classic three-electrode system was used in the electrochemical measurements. Potentiodynamic polarization was started after CE for $15 \mathrm{~min}$ and swept from $-400 \mathrm{mV}$ relative to corrosion potential at a fixed rate of $1 \mathrm{mV} / \mathrm{s}$ until a current density of $10 \mathrm{~mA} / \mathrm{cm}^{-2}$ was reached.

In order to investigate the mechanism of material removal during $\mathrm{CE}$, specimens were examined after fixed cavitation intervals. The microstructures of HNSS and the eroded surfaces of the samples examined using XL20 scanning electron microscopy (SEM). The crystal structures of the HNSSs were studied by XRD (Philips PW3710), using $\mathrm{Cu}-K_{\alpha}$ radiation generated at $40 \mathrm{kV}$ and $35 \mathrm{~mA}$.

\section{RESULTS AND DISCUSSION}

\subsection{Material characterization}

Figure 1 shows the SEM morphology of the as-received HNSS. It is clear that HNSS consisted of a typical $\gamma$ (austenitic) phase matrix with twin boundaries and precipitated $\mathrm{Cr}_{2} \mathrm{~N} .{ }^{18,19}$ The EDS of HNSS and precipitated particles were shown in Table 2. The XRD analysis in Figure 2 shows that HNSS was in a single $\gamma$ phase, while the dispersed precipitated $\mathrm{Cr}_{2} \mathrm{~N}$ cannot be detected.

Table 2: EDS of as-received HNSS and $\mathrm{Cr}_{2} \mathrm{~N}$, in mass fractions $(w / \%)$

\begin{tabular}{|c|c|c|c|c|c|c|}
\hline Area & $\mathrm{Fe}$ & $\mathrm{Cr}$ & $\mathrm{Mn}$ & $\mathrm{Mo}$ & $\mathrm{Si}$ & $\mathrm{N}$ \\
\hline 1 & 5.01 & 78.83 & 4.03 & 0.72 & 0.58 & 10.83 \\
\hline 2 & 61.32 & 18.33 & 17.37 & 2.98 & - & - \\
\hline
\end{tabular}


Y. X. QIAO et al.: CAVITATION EROSION PROPERTIES OF A NICKEL-FREE HIGH-NITROGEN Fe-Cr-Mn-N STAINLESS STEEL

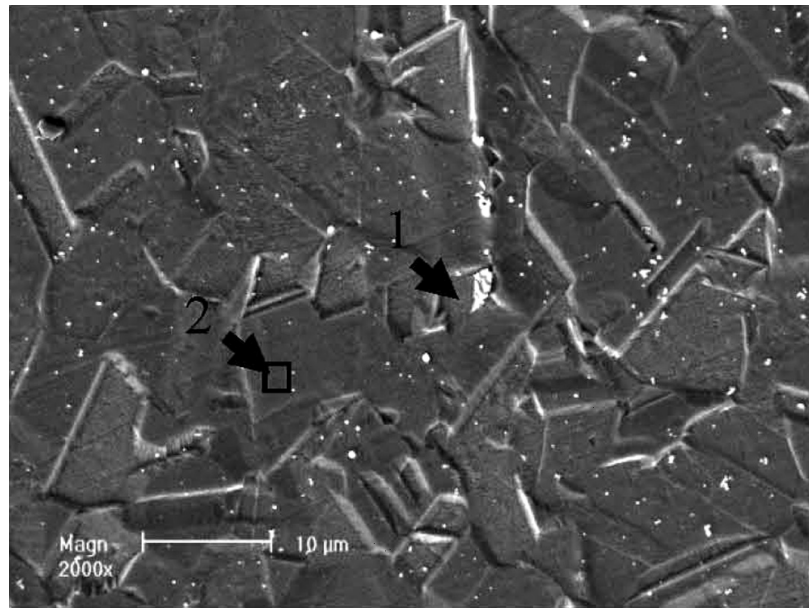

Figure 1: SEM micrograph of as-received HNSS

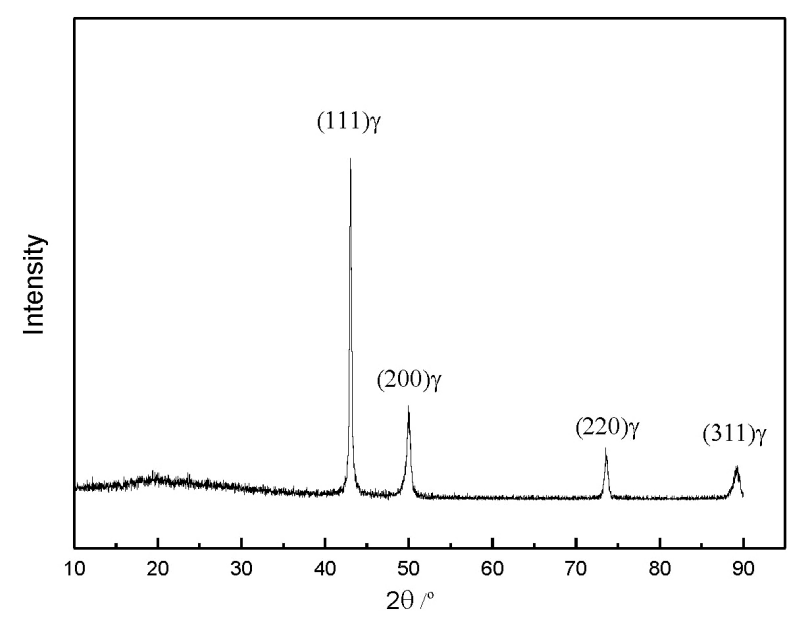

Figure 2: XRD of as-received HNSS

\subsection{Mass loss}

Figure 3 presents the mass-loss curve versus CE time, which indicates that the $\mathrm{CE}$ resistance can be influenced by the corrosivity of the tested solution. After $\mathrm{CE}$ for $8 \mathrm{~h}$, the mass loss of HNSS in $0.5-\mathrm{M} \mathrm{NaCl}$ was 1.17 times that in distilled water. In distilled water, the mass loss rate curves of HNSS could be divided into two stages. The mass loss rate was characterized by a very low value and kept almost constant within $4 \mathrm{~h}$, and it could be regarded as an incubation period. After a $\mathrm{CE}$ time of $4 \mathrm{~h}$ the mass-loss rate increased quickly and linearly with the CE time. Generally, it is believed that the duration of incubation time depends on how long microcracks need to initiate by collapse. Material with longer incubation periods is considered to have a superior $\mathrm{CE}$ resistance. In contrast, the mass loss rate was characterized by a high value in the $0.5-\mathrm{M} \mathrm{NaCl}$ solution. After $\mathrm{CE}$ for $2 \mathrm{~h}$, the mass-loss rate reached a constant stage. This indicated that the $\mathrm{CE}$ resistance of HNSS in distilled water was better than that in a $\mathrm{NaCl}$ solution. The initiation and propagation of microcracks can be facilitated by corrosion media. This could be

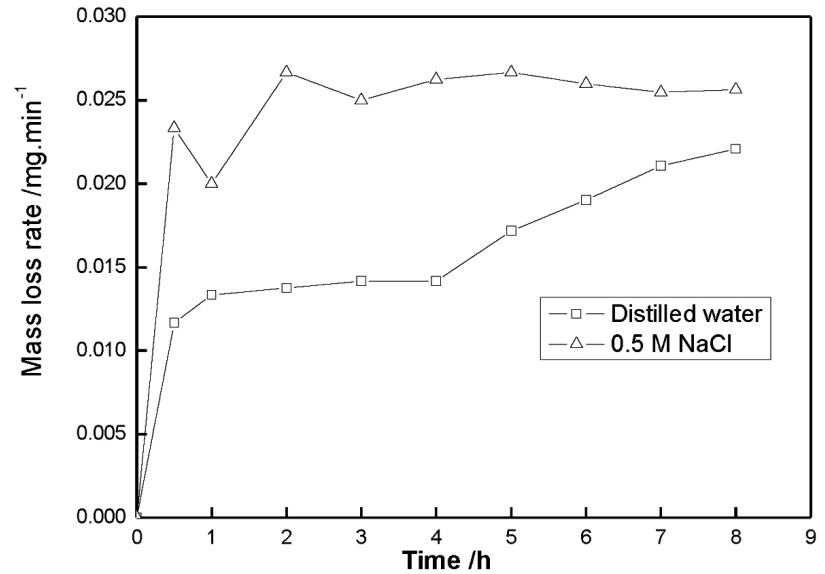

Figure 3: Mass-loss rate for HNSS in tested solutions under CE condition

further confirmed by SEM observation in the later stages.

\subsection{Electrochemical behaviour}

In order to investigate the effect of corrosion on $\mathrm{CE}$ behaviour of HNSS, polarization curves were tested under static and $\mathrm{CE}$ conditions in $0.5-\mathrm{M} \mathrm{NaCl}$ and shown in Figure 4. It can be seen that the corrosion behaviour of the HNSS under both static conditions and CE conditions exhibited similar polarization behaviour. The anodic current density gradually increased by increasing the electrode potential under both static and CE conditions. The corrosion potential under static and CE condition was $-212.05 \mathrm{mV}_{\mathrm{SCE}}$ and $-506.96 \mathrm{mV}_{\mathrm{SCE}}$, respectively. The corrosion current density $\left(i_{\text {corr }}\right)$ of HNSS under static and CE conditions is $1.39 \mu \mathrm{A} / \mathrm{cm}^{2}$ and $133.97 \mu \mathrm{A} / \mathrm{cm}^{2}$, respectively. The results obtained indicating that cavitation shifted the corrosion potential to a negative direction and increased the anodic current densities by two orders of magnitude. The corrosion of HNSS in the static condition was controlled by the

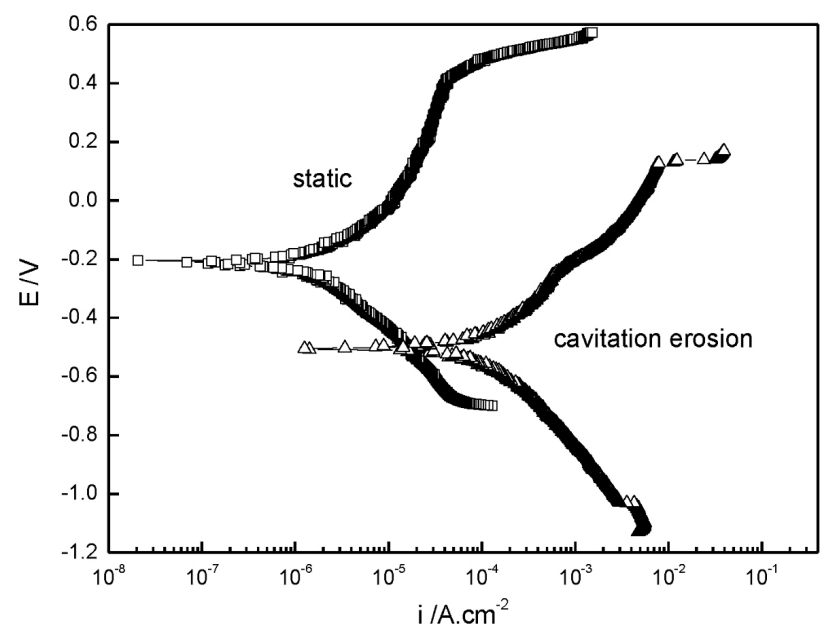

Figure 4: Potentiodynamic polarization curves for HNSS in $0.5 \mathrm{M}$ $\mathrm{NaCl}$ and $0.5 \mathrm{MHCl}$ solution under static and $\mathrm{CE}$ condition 
dissolution of the passive film and repassivation of the metal. The passive film on the surface of HNSS can be damaged locally by a random collapse of bubbles and results in the dissolution of material and will cause the total anodic current density to increase a lot. The influence of $\mathrm{CE}$ on the corrosion potential is attributed to the reason that a relatively stronger influence on anodic reaction than that of cathodic reaction. ${ }^{20,21}$ It is well known that chloride ions will induce pitting corrosion in stainless steels in static conditions. Under CE conditions, stirring of the electrolyte and film destruction occur simultaneously, ${ }^{22}$ both upsetting the local environment for pit growth. Thus the effect of cavitation remains mechanical, even in the presence of chloride ions. ${ }^{17}$

\subsection{Evolution of CE damage of HNSS}

The microstructure change of HNSS in each period was observed continuously. Figure $\mathbf{5}$ shows the surface micrographs of HNSS after CE for different time intervals in distilled water. Figure 5a shows the appearance of the surface after a CE time of $1 \mathrm{~h}$. The eroded surface was characterized by the formation of surface undulations, labelled A, and cavities, labelled B, caused by material removal appeared along grain boundaries can be clearly seen. This provided evidence that $\mathrm{CE}$ damage was firstly initiated at grain boundaries and is consistent with the results reported by S. Z. Luo, ${ }^{6}$ who reported that $\mathrm{CE}$ damage arising from material extrusions at grain boundaries in polycrystalline materials. Slip lines, labelled $\mathrm{C}$, and deformed twins, labelled $\mathrm{D}$, can also be seen clearly inside austenite grains. The surface exhibited plastic deformation in the form of surface undulations as well as the appearance of grain boundaries, slip bands, and twin boundaries in incubation periods. ${ }^{10,12}$ Figure 5b shows the appearance of the surface after a $\mathrm{CE}$ time of $3 \mathrm{~h}$. It can be seen that material removal was preferentially at the grain boundaries and cavities, then growth towards the inner region of the grains. The mass

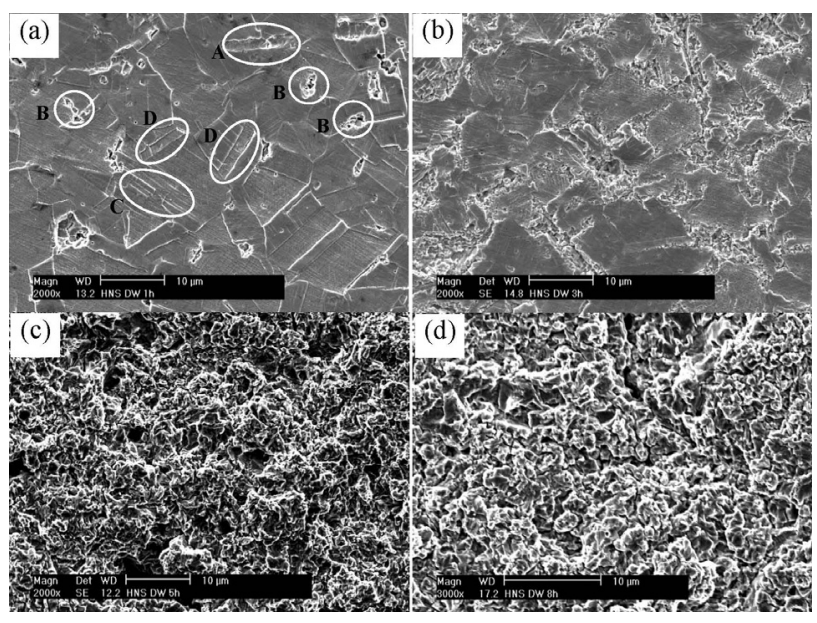

Figure 5: SEM images of HNSS after CE for : a) $1 \mathrm{~h}$, b) $3 \mathrm{~h}$, c) $5 \mathrm{~h}$ and d) $8 \mathrm{~h}$ in distilled water: A- surface undulations, B- cavities, Cslip lines, D-deformed twins removal inside the grains starts at slip lines and deformed twins. This is consistent with the results reported by Mills and Knutsen ${ }^{12}$. It could also be seen that some grains are much more deformed than others, indicating significant plasticity anisotropy at the mesoscale, which can be addressed to different values of the resolved shear stress inside each grain. ${ }^{15}$ The damaged surface after CE for $5 \mathrm{~h}$ is shown in Figure 5c, in which craters about $2-5 \mu \mathrm{m}$ in diameter and cracks can be observed. The craters were created due to the removal of material by a combined effect of microfatigue and microcrack formation. After CE for $8 \mathrm{~h}$, the propagation and connection of the microcracks by fatigue at continuous impact of bubble collapse, give to the larger craters and wide cracks, as shown in Figure 5d. This is consistent with the mass-loss rate presented in Figure 3 that larger bulk material was lost in this period.

The morphologies of the eroded surfaces in $0.5-\mathrm{M}$ $\mathrm{NaCl}$ were slightly different to that in distilled water for the same time intervals. Figure 6 shows surface micrographs of HNSS after CE for different time intervals in $0.5-\mathrm{M} \mathrm{NaCl}$. Figure 6a indicates that plastic deformation and surface undulations are more serious than that in distilled water, more slip lines formed inside grains and discontinuous at grain boundaries. The active dissolution of HNSS can be clearly seen on the surface, especially at site of slip line intersections. After CE for $3 \mathrm{~h}$, the cavitated surface was very rough and only a little original surface be preserved, deep gaps and cracks due to the material removal at the grain boundaries can be clearly seen, as shown in Figure 6b. These results suggested that mass loss of HNSS in $0.5-\mathrm{M} \mathrm{NaCl}$ solution was significantly enhanced and consistent with the results that mass loss is almost constant in $0.5-\mathrm{M}$ $\mathrm{NaCl}$ solution after the initial increase. Figure $\mathbf{6 c}$ and $\mathbf{6 d}$ shows the surface of HNSS after CE for $5 \mathrm{~h}$ and $8 \mathrm{~h}$. The eroded surface of the HNSS was found to be similar to that in distilled water in that they are all characterized by the formation of craters and fatigue cracks on the sample

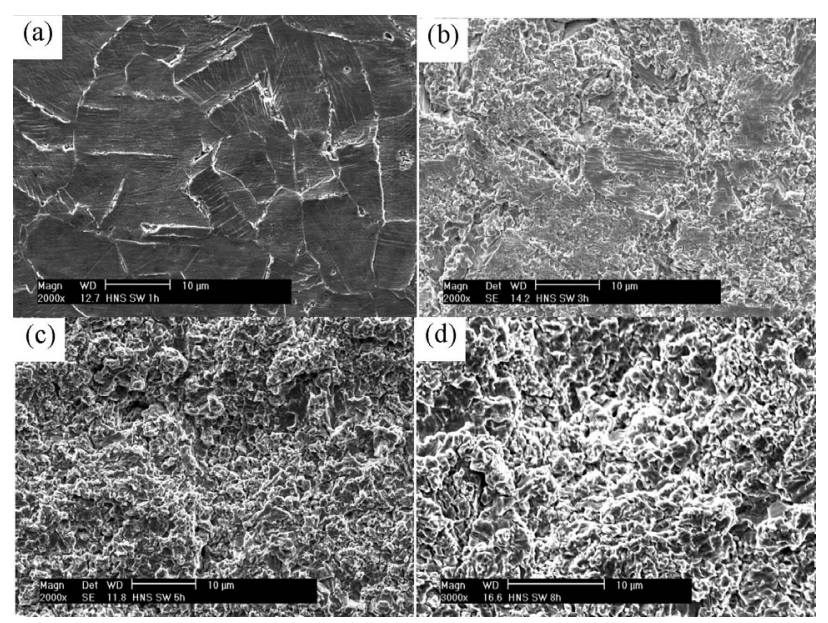

Figure 6: SEM images of HNSS after CE for: a) $1 \mathrm{~h}$, b) $3 \mathrm{~h}, \mathrm{c}) 5 \mathrm{~h}$ and d) $8 \mathrm{~h}$ in $0.5 \mathrm{M} \mathrm{NaCl}$ solution 
surface. The size of cater is smaller than that in the distilled water. This indicates corrosion played an important role in that it can promote the crack initiation and propagation of the cracks.

The overall CE rate is constituted by an erosion rate, a corrosion rate and a synergistic effect of erosion and corrosion. ${ }^{15-17,23-25}$ The synergistic effect of electrochemical and mechanical factor produced far more damage than if each acted separately in a large number of systems. The total mass loss is composed of erosion mass loss, corrosion mass loss and synergistic effect of erosion and corrosion. In corrosive media the total material loss can be expressed by: ${ }^{20}$

$$
W_{\mathrm{T}}+W_{\mathrm{E}}+W_{\mathrm{C}}+W_{\mathrm{S}}=W_{\mathrm{C}}+W_{\mathrm{E}}+W_{\mathrm{CIE}}+W_{\mathrm{EIC}}
$$

where $W_{\mathrm{T}}$ is the total CE material loss, $W_{\mathrm{E}}$ is the component of pure erosion part, $W_{\mathrm{C}}$ is the fraction of pure corrosion under static condition, $W_{\mathrm{S}}$ is volume loss rate of synergism, $W_{\mathrm{EIC}}$ is the fraction of erosion induced corrosion, $W_{\mathrm{CIE}}$ is the fraction of erosion induced corrosion.

Table 3: Mass loss induced by pure corrosion $\left(W_{\mathrm{C}}\right)$, pure erosion $\left(W_{\mathrm{E}}\right)$, erosion-induced corrosion $\left(W_{\mathrm{EIC}}\right)$ and corrosion induced erosion $\left(W_{\mathrm{CIE}}\right)$ and ratios of each factor for HNSS in $0.5 \mathrm{M} \mathrm{NaCl}$

\begin{tabular}{|c|c|c|c|c|c|c|c|c|}
\hline \multicolumn{5}{|c|}{ Mass loss $(\mathrm{mg})$} & \multicolumn{4}{|c|}{ Damage fraction $(\%$} \\
\hline$W_{\mathrm{T}}$ & $W_{\mathrm{C}}$ & $W_{\mathrm{E}}$ & $W_{\mathrm{EIC}}$ & $W_{\mathrm{CIE}}$ & $f_{\mathrm{C}}$ & $f_{\mathrm{E}}$ & $f_{\mathrm{EIC}}$ & $f_{\mathrm{CIE}}$ \\
\hline 12.45 & 0.01 & 10.60 & 1.10 & 0.74 & 0.08 & 85.14 & 8.83 & 5.95 \\
\hline
\end{tabular}

Note: $f_{\mathrm{C}}$ ratio of pure corrosion, $f_{\mathrm{E}}$ ratio of pure erosion, $f_{E I C}$ ratio of erosion-induced corrosion, $f_{\mathrm{CIE}}$ ratio of corrosion-induced erosion, $\mathrm{W}_{\mathrm{T}}$ mass loss induced by $\mathrm{CE}$

In present work, $W_{\mathrm{T}}$ was the cumulative mass loss under $\mathrm{CE}$ conditions for $8 \mathrm{~h}$ in $0.5-\mathrm{M} \mathrm{NaCl}$. $W_{\mathrm{E}}$ were the cumulative mass loss under $\mathrm{CE}$ condition for $8 \mathrm{~h}$ in distilled water. $W_{\mathrm{C}}$ was calculated from the $i_{\text {corr }}$ in the polarization curve under static conditions according to Faraday's law. $W_{\text {EIC }}$ was calculated from the $i_{\text {corr }}$ in the polarization curve under $\mathrm{CE}$ and $W_{\mathrm{CIE}}$ could be obtained from Equation (1). Table 3 lists the parameters described above. It indicated that the contribution of the synergistic component ( $W_{\mathrm{EIC}}$ and $W_{\mathrm{CIE}}$ ) to $W_{\mathrm{T}}$ was $14.78 \%$, which meant that the mechanical effect was the main factor for the CE-corrosion behaviour of HNSS, but at the same time the contribution of corrosion cannot be neglected.

\section{CONCLUSION}

The cumulative mass loss of the HNSS in 0.5-M $\mathrm{NaCl}$ was about 1.17 times that in distilled water. CE shifted the corrosion potential of HNSS to cathodic direction in $0.5-\mathrm{M} \mathrm{NaCl}$. The anodic reactions under cavitation conditions were two orders of magnitude faster than that in quiescent conditions. Cavitation erosion damage began at the grain, twin boundaries and interfaces between $\mathrm{Cr}_{2} \mathrm{~N}$. In the total cumulative mass loss under CE corrosion conditions, the mechanical effect played a key role for HNSS and the synergistic component was $14.78 \%$ in $0.5-\mathrm{M} \mathrm{NaCl}$. The propaga- tion and connection of cracks can be facilitated by the corrosivity of the tested media.

\section{Acknowledgements}

We wish to express our gratitude to the financial support of the National Natural Science Foundation of China (Nos.51401092, 51409129, 51131008, 51434004, U1435205 and 51304041) and Natural Science Foundation of Jiangsu Province (BK20140504) for the finance support of this research.

\section{REFERENCES}

${ }^{1}$ A. Karimi, J. L. Martin, Cavitation erosion of materials, Int. Mater. Rev., 31 (2013), 1-26, doi:10.1179/imtr.1986.31.1.1

${ }^{2}$ M. Moallemi, A. Zarei-Hanzaki, H. S. Baghbadorani. Evolution of microstructure and mechanical properties in a cold deformed nitrogen bearing TRIP-assisted duplex stainless steel after reversion annealing. Mater. Sci. Eng. A, 683 (2016), 83-89, doi:10.1016/ j.msea.2016.10.105

${ }^{3}$ F. Y. Dong, P. Zhang, J. C. Pang, Y. B. Ren, K. Yang, Z. F. Zhang, Strength, damage and fracture behaviors of high-nitrogen austenitic stainless steel processed by high-pressure torsion, Scripta Mater., 96 (2015), 5-8, doi:10.1016/j.scriptamat.2014.09.016

${ }^{4}$ Y. G. Zheng, S. Z. Luo, W. Ke, Cavitation erosion-corrosion behaviour of CrMnB stainless overlay and $0 \mathrm{Cr} 13 \mathrm{Ni} 5 \mathrm{Mo}$ stainless steel in $0.5 \mathrm{M} \mathrm{NaCl}$ and $0.5 \mathrm{M} \mathrm{HCl}$ solutions, Tribol. Int., 41 (2008), 1181-1189, doi:10.1016/j.triboint.2008.02.011

${ }^{5}$ H. Hänninen, J. Romu, R. Ilola, J. Tervo, A. Laitinen, Effects of processing and manufacturing of high nitrogen-containing stainless steels on their mechanical, corrosion and wear properties, J. Mater. Process. Technol., 117 (2001), 424-430, doi:10.1016/S09240136(01)00804-4

${ }^{6}$ S. Z. Luo, Y. G. Zheng, W. Liu, H. M Jing, Z. M Yao, W. Ke, Cavitation erosion behavior of CrMnN duplex stainless steel in distilled water and $3 \% \mathrm{NaCl}$ solution, J. Mater. Sci. Technol., 19 (2003), 346-350, doi:10.3321/j.issn:1005-0302.2003.04.016

${ }^{7}$ W. Liu, Y. G. Zheng, C. S. Liu, Z. M. Yao, W. Ke, Cavitation erosion behavior of Cr-Mn-N stainless steels in comparison with 0Cr13Ni5Mo stainless steel, Wear, 254 (2003), 713-722, doi:10.1016/S0043-1648(03)00128-5

${ }^{8}$ H. Berns, S. Siebert, High nitrogen austenitic cases in stainless steels. ISIJ Inter., 36 (1996), 927-931, doi:10.2355/isijinternational. 36.927

${ }^{9}$ W. T. Fu, Y. Z. Zheng, X. K. He, Resistance of a high nitrogen austenitic steel to cavitation erosion, Wear, 249 (2001), 788-791, doi:10.1016/S0043-1648(01)00811-0

${ }^{10}$ P. Niederhofer, L. Richrath, S. Huth, W. Theisen, Influence of conventional and powder-metallurgical manufacturing on the cavitation erosion and corrosion of high interstitial $\mathrm{CrMnN}$ austenitic stainless steels, Wear, 360-361 (2016), 67-76, doi:10.1016/j.wear.2016. 04.017

${ }^{11}$ W. T. Fu, Y. B. Yang, T. F. Jing, Y. Z. Zheng, M. Yao, The resistance to cavitation erosion of CrMnN stainless steels, J. Mater. Eng. Perform., 7 (1998), 801-804, doi:10.1361/105994998770347396

${ }^{12}$ D. J. Mills, R.D. Knutsen, An investigation of the tribological behaviour of a high-nitrogen $\mathrm{Cr}-\mathrm{Mn}$ austenitic stainless steel, Wear, 215 (1998), 83-90, doi:10.1016/S0043-1648(97)00273-1

${ }^{13}$ J. F. Santos, C. M. Garzón, A. P. Tschiptschin, Improvement of the cavitation erosion resistance of an AISI 304L austenitic stainless steel by high temperature gas nitriding, Mater. Sci. Eng. A, 382 (2004), 378-386, doi:10.1016/j.msea.2004.05.003

${ }^{14}$ D. H. Mesa, C. M. Garzón, A. P. Tschiptschin, Influence of coldwork on the cavitation erosion resistance and on the damage mechanisms in high-nitrogen austenitic stainless steels, Wear, 271 (2011), 1372-1377, doi:10.1016/j.wear.2011.01. 063 


\section{MATERIALI IN TEHNOLOGIJE/MATERIALS AND TECHNOLOGY (1967-2017) - 50 LET/50 YEARS}

\section{Y. X. QIAO et al.: CAVITATION EROSION PROPERTIES OF A NICKEL-FREE HIGH-NITROGEN Fe-Cr-Mn-N STAINLESS STEEL}

${ }^{15}$ Y. X. Qiao, S. Wang, B. Liu, Y. G. Zheng, H. B. Li, Z. H. Jiang, Synergistic effect of corrosion and cavitation erosion of high nitrogen stainless steel, Acta Metall. Sin., 52 (2016), 233-240, doi:10.11900/0412.1961.2015.00282

${ }^{16}$ A. Al-Hashem, P. G. Cacere, A. Abdullah, H. M. Shalaby, Cavitation corrosion of duplex stainless steel in seawater, Corrosion, 53 (1997), 103-113, doi: $10.5006 / 1.3280438$

${ }^{17}$ C. T. Kwok, F. T. Cheng, H. C. Man, Synergistic effect of cavitation erosion and corrosion of various engineering alloys in $3.5 \% \mathrm{NaCl}$ solution, Mater. Sci. Eng. A, 290 (2000), 145-154, doi:10.1016/ S0921-5093(00)00899-6

${ }^{18}$ T. H. Lee, C. S. Oh, C. G. Lee, S. J. Kim, S. Takaki, Precipitation of $\sigma$-phase in high-nitrogen austenitic $18 \mathrm{Cr}-18 \mathrm{Mn}-2 \mathrm{Mo}-0.9 \mathrm{~N}$ stainless steel during isothermal aging, Scripta Mater., 50 (2004), 1325-1328, doi:10.1016/j.scriptamat.2004.02.013

${ }^{19}$ H. Y. Ha, H. S. Kwon. Effects of $\mathrm{Cr}_{2} \mathrm{~N}$ on the pitting corrosion of high nitrogen stainless steels, Electrochimica Acta, 52 (2007), 2175-2180, doi:10.1016/j.electacta.2006.08.034

${ }^{20}$ S. Z. Luo, M. C. Li, W. Ke, Z. M. Yao, Y. G. Zheng, Effect of cavitation on corrosion behavior of 20SiMn low-alloy steel in 3\% sodium chloride solution, Corrosion, 59 (2003), 597-605, doi:10.5006/ 1.3277590
${ }^{21}$ Y. G. Zheng, S. Z. Luo, W. Ke, Effect of passivity on electrochemical corrosion behavior of alloys during cavitation in aqueous solutions, Wear, 262 (2007), 1308-1314, doi:10.1016/j.wear.2007.01.006

${ }^{22}$ B. Vyas. I. L.H. Hansson, The cavitation erosion-corrosion of stainless steel, Corro. Sci., 30 (1990), 761-770, doi:10.1016/0010938X(90)90001-L

${ }^{23}$ J. Basumatary, M. Nie, R. J. K. Wood, The Synergistic Effects of cavitation erosion-corrosion in ship propeller materials, J. Bio. Tribo. Corro., 1 (2015), 1-12, doi:10.1007/s40735-015-0012-1

${ }^{24}$ R. J. K. Wood, S. A. Fry, The synergistic effect of cavitation erosion and corrosion for copper and cupro-nickel in seawater, J. Fluids Eng., 111 (1989), 271-277, doi:10.1115/1.3243641

${ }^{25}$ S. Hong, Y. P. Wu, J. Zhang, Y. G. Zheng, J. Lin, Synergistic effect of ultrasonic cavitation erosion and corrosion of $\mathrm{WC}-\mathrm{CoCr}$ and FeCrSiBMn coatings prepared by HVOF spraying, Ultrason. Sonochem., 31 (2016), 563-569. doi:10.1016/j.ultsonch.2016.02.011 